\title{
O lugar da teatralidade na dança contemporânea
}

\section{Resumo}

O presente artigo investiga a cena híbrida da dança ocidental pós-geração de 1970 a partir da noção de teatralidade. Busca refletir sobre a pertinência da teatralidade como instrumento de análise das poéticas coreográficas contemporâneas e sobre os possíveis procedimentos que efetivam uma lógica peculiar à linguagem da dança. Discute certas estratégias de produção e funcionamento da teatralidade que permitem sua manifestação distintiva na dança contemporânea.

Palavras-chave: Dança contemporânea; teatralidade; dança cênica.

\section{Abstract}

This paper investigates the hybrid scene of western dance post-1970 generation from the notion of theatricality. It reflects on the relevance of theatricality as a tool for analysis of contemporary poetic choreography and the possible procedures that actualize a peculiar logic to the language of dance. It discusses certain strategies of the theatricality production and working that allow its distinctive manifestation in contemporary dance.

Keywords: Contemporary dance; theatricality; scenic dance.

A cena da dança dos últimos decênios expõe um panorama de produção complexo e multiforme, marcado pelo hibridismo, heterogeneidade, fragmentação e transversalidade de formas e discursos. Esse caráter plural torna-se visível também nos modos de ação de seus criadores e na oferta extremamente generosa de técnicas e metodologias de trabalho de que dispõem para confecção de sua arte.

Ao longo de todo o século XX, a reconsideração de certezas (FÉRAL, 2004) foi condição vivenciada por todas as artes do espetáculo que, perdendo suas evidências, foram forçadas a se redefinirem. Tendo como mais recuados acontecimentos as intervenções multidisciplinares das vanguardas estéticas do início do século XX, novas formas de escrita cênica, marcadamente fronteiriças e mutantes, não cessaram de se desdobrar num sem-número de experiências na cena contemporânea. Assim, se a transgressão de fronteiras não é fato recente, a fluidez e insistência com que

\footnotetext{
${ }^{1}$ Bailarina, criadora e pesquisadora da dança. Docente do Curso de Graduação em Dança do Instituto de Artes da Unicamp. Pós-Doutoranda em Artes pelo Núcleo Interdisciplinar de Pesquisas Teatrais/LUME/Unicamp, Campinas, SP. Professora e Instrutora do Método Feldenkrais de Educação Somática.
} 
as artes da cena a vem efetuando é, no entanto, fenômeno que merece destaque e, sobretudo, investigação.

Com o intuito de enfrentar conceitualmente espécies cênicas que têm como especificidade a quebra de limites entre os gêneros e a dissolução das distinções formais entre suas práticas, diversos teóricos do teatro e da performance têm recorrido à noção de teatralidade como um dos instrumentos de análise de tais fenômenos (FERNANDES, 2011). A inesgotável produção de ensaios teóricos surpreende e demonstra a relevância que o assunto assumiu para pesquisadores da área.

Entretanto, termos como teatral e teatralidade há muito deixaram de ser qualificativos restritos ao âmbito específico do teatro, passando a gozar de ampla difusão em campos díspares como a arte, a etnografia, a sociologia, a psicologia e a linguística (CORNAGO, 2009). Esta condição de transcendência transformou-as em noções de difícil delimitação, sendo abordadas por diferentes estudiosos em sua polissemia e, muitas vezes, de formas divergentes e até mesmo contraditórias.

Em se tratando do campo de estudos da dança, o conceito tem sido, no entanto, escassamente explorado como ferramenta de operação teórica, fato que tem me instigado a refletir a respeito de sua pertinência como vetor de leitura das escritas coreográficas contemporâneas e dos possíveis procedimentos de produção que efetivam uma lógica peculiar à linguagem da dança. Trata-se, nesse caso, de tentar compreender a noção tanto no âmbito dos fundamentos teóricos, quanto da prática cênica (seu funcionamento), colocando em enfoque não apenas o espetáculo produzido recepção e resultados exteriores, mas, sobretudo, o processo de sua criação, mecanismos e funcionamentos internos. Desta tentativa, as seguintes interrogações têm se imposto: O que permite a emergência do conceito de teatralidade na dança? Quais são os elementos indispensáveis para sua produção? Há, de fato, especificidades que permitam distinguir sua manifestação no campo da dança de outras práticas artísticas? Quais são as estratégias que possibilitam reconhecer seus modos de inscrição e funcionamento na cena coreográfica?

Minha afinidade com a temática da teatralidade coreográfica - termo emprestado da historiadora da dança Michèle Febvre (1995) - teve início durante o processo de pesquisa de meu doutoramento em artes ${ }^{2}$, no qual procurei discernir sobre o conceito em

\footnotetext{
${ }^{2}$ Minha pesquisa de doutorado teve lugar no Instituto de Artes da Unicamp, entre os anos de 2005 e 2009 , resultando na tese intitulada "Raízes da Teatralidade na Dança Cênica: recortes de uma tendência paulistana".
} 
relação tanto a um contexto determinado - o período compreendido entre a fundação do Teatro Galpão (1974) e a criação do Movimento Teatro-Dança 90 (1993) na cidade de São Paulo -, quanto a experiências cênicas específicas - a importante trajetória e produção das coreógrafas e bailarinas Célia Gouvêa e Sônia Mota dentro do recorte contextual citado. Elegendo algumas das obras que se tornaram referência da criação das artistas no período, a intenção foi investigar como a noção de teatralidade se comporta no contato com práticas cênicas concretas, buscando capturar elementos elucidativos de determinados processos de teatralização peculiares aos trabalhos das coreógrafas, seja nos modos de gestão da corporeidade dançante, nos procedimentos de criação empregados ou na manipulação dos diferentes materiais cênicos para formalização da obra.

Sem a intenção de oferecer uma definição normativa para o conceito de teatralidade na dança, nem fornecer respostas conclusivas às questões acima formuladas, busco expor a seguir algumas possíveis chaves para a compreensão do fenômeno no campo do espetáculo coreográfico e de sua potência como referencial de análise das práticas artísticas da dança contemporânea.

Partindo do pressuposto que a noção de teatralidade se configurou na dança com características e propriedades diferenciadas daquelas relacionadas ao teatro, nesta breve exposição retomo parte das perspectivas e discussões desenvolvidas por Michèle Febvre, em sua obra Danse Contemporaine et Théâtralité (Art Nomade, 1995), sobretudo pelo fato da autora ser uma das poucas teóricas da dança a tratar diretamente da temática. Apoio-me também em pensadores como Michel Bernard, Patrice Pavis, Roland Barthes, Josette Féral, Antonin Artaud, Silvia Fernandes, Luiz Fernando Ramos, Óscar Cornago, dentre outros, por seus estudos significativos e abundantes sobre o assunto.

\section{O teatral na dança}

Em seus estudos sobre a temática, Michèle Febvre (1995) coloca em relevo a polissemia do conceito de teatralidade. Recorda que sua origem remonta à Rússia revolucionária do início do século XX, desenvolvendo-se inicialmente a partir dos questionamentos de Vsevolod E. Meierhold (1874-1940) e Nikolai N. Evreïnof (1879-1953) e seguidamente por Antonin Artaud (1896-1948), Edward Gordon Craig (1872-1966) e Bertolt Brecht (1898-1966), os quais podem ser considerados pioneiros na busca pelo afastamento ou libertação do teatro com relação ao texto dramático e ao discurso literário, fundado na palavra e nas categorias de imitação e ação. 
Seguindo essa linha de influências, Patrice Pavis (1999, p. 372) define teatralidade como "aquilo que, na representação ou no texto dramático, é especificamente teatral (ou cênico)", referenciando a reivindicação artaudiana de que a cena deve ser preenchida por uma linguagem física e concreta, distinta da palavra, que se dirija antes de tudo aos sentidos:

Como é que o teatro, pelo menos no teatro tal como o conhecemos na Europa, ou melhor, no Ocidente, tudo o que é especificamente teatral, isto é, tudo o que não obedece à expressão através do discurso, das palavras ou, se preferirmos, tudo que não está contido no diálogo (o próprio diálogo considerado em função de suas possibilidades de sonorização da cena, e das exigências dessa sonorização) seja deixado em segundo plano? ${ }^{3}$

Mesmo quando trata da linguagem articulada, Artaud considera que é somente fazendo aquilo que denomina metafísica da linguagem que a expressão cênica poderá nos conduzir à verdadeira poesia:

\begin{abstract}
Fazer a metafísica da linguagem articulada é fazer com que a linguagem sirva para expressar aquilo que habitualmente ela não expressa: é usá-la de um modo novo, excepcional e incomum, é devolver-lhe suas possibilidades de comoção física, é dividi-la e distribuí-la ativamente no espaço, é tomar as entonações de uma maneira concreta absoluta e devolver-lhes o poder que teriam de dilacerar e manifestar realmente alguma coisa [...] é, enfim, considerar a linguagem sob a forma do Encantamento. ${ }^{4}$
\end{abstract}

Ao teorizar sobre o fenômeno teatral, Roland Barthes (2009a) se aproxima das ideias de Artaud: opõe a polifonia informacional proveniente dos diversos meios cênicos utilizados pelo espetáculo (cenário, figurino, iluminação, espaço, atores, gestos, fala) à narrativa literária linear, definindo teatralidade como "uma espessura de signos" - signos que se dispõem em contraponto, isto é, de forma sucessiva e simultânea, criando uma rede semântica complexa e densa.

A recusa à primazia do texto dramático e à representação de uma realidade cênica naturalista e verossimilhante fará da teatralidade objeto de inúmeras experimentações estéticas. A esse respeito, Luiz Fernando Ramos (2006) acrescenta que é possível pensar toda a tradição do teatro moderno, de fins do século XIX em diante, como expressão de uma crescente valorização do espetacular em relação às formas dramáticas, em que se vê substituir uma poética do drama por uma poética da cena, isto é, uma poética não mais centrada no drama como eixo principal de produção do sentido, mas numa pluralidade de canais de enunciação. Essa tendência emergirá da aplicação de processos inéditos de produção da materialidade cênica, com ênfase nas relações do teatro com

\footnotetext{
${ }^{3}$ ARTAUD, Antonin. O teatro e seu duplo. Tradução de Teixeira Coelho. 3.ed. São Paulo: Martins Fontes, 2006, p.35.

${ }^{4}$ Ibid., p.46-47.
} 
outras expressões artísticas, resultando no aparecimento de diferentes teatralidades ao que Ramos denomina de formas transgênicas ou bastardas.

Sobretudo a partir de meados da década de 1960, a música e a dança passam a interessar-se intensamente pela questão da teatralidade em decorrência do movimento transdisciplinar que favorece o cruzamento de fronteiras e a contaminação recíproca das diferentes artes (FEBVRE, 1995). Como resultado, assistimos, dos anos de 1970 em diante, uma tendência crescente por parte dos novos coreógrafos de reconduzir a dança à narratividade e à produção de novas redes semânticas, lançando mão de recursos teatralizantes para a criação coreográfica.

Mas se a dança cênica é, antes de tudo, uma forma teatral - no sentido original de que existe, de fato, para se dar a ver, para ser fruída, testemunhada -, como podemos então determinar o que nela produz efeito de teatro? Este efeito de teatro deve ser especulado como uma qualidade imanente à própria dança ou como algo exterior do qual a dança se investe para criar tal impressão? Além disso, o teatral e a teatralidade não seriam problemáticas reinventadas por cada época, em movimentos de transgressão, reconciliação ou substituição a metas artísticas precedentes?

Febvre (1995) recorda-nos que, ao longo de toda a sua história, a dança ocidental oscilou entre ser forma e expressão, inserindo-se permanentemente na discussão relativa à dualidade produção de linguagem / produção de sentido. Assim, se de um lado, a dança da chamada geração pós-moderna do início de 1960, sobretudo a americana, emergiu da recusa aos artifícios do espetacular e da efetividade teatral tendendo a uma antiteatralidade ${ }^{5}$; de outro, as correntes subsequentes voltaram a se perguntar como significar, num movimento que não foi nem de reação, nem de subjugação às tradições da dança (sejam recentes ou remotas).

Este é o caso da danse nouvelle e do tanztheater europeus. Em parte, ambos nascerão como resposta à abstração da dança americana. Ao dizer em parte, realço o fato destas duas formas não terem se desenvolvido como movimentos de recusa aos preceitos da arte daquela geração, a exemplo do que ocorreu com a dança moderna em relação ao balé. O contato de artistas europeus com as obras de americanos pós-modernistas como Caroline Carlson, Merce Cunningham, Alwin Nikolais e Trisha

\footnotetext{
${ }_{5}^{5}$ Silvia Fernandes (2010) especula se, no contexto de quebra de paradigmas que definiu o teatro moderno, o antiteatralismo não foi, ao invés de mera oposição, uma força produtiva de experiências radicais que geraram outro tipo de teatralidade, em resposta aos modelos teatrais em vigor. Este mesmo aspecto pode ser avaliado para o campo de acontecimentos da dança.
} 
Brown, mas também com o butoh japonês e com o teatro contemporâneo, sobretudo o teatro do absurdo, produziu efeitos assimilatórios (CANTON, 1994), influenciando a formulação de estilos narrativos distintos e, por que não dizer, de novas teatralidades.

Após as experiências dos coreógrafos americanos com a abstração e os gestos formalistas, houve um retorno ao fascínio pelas narrativas de histórias e por conteúdos emocionais como fonte coreográfica. Porém, essa tendência não significou um retorno aos estilos narrativos do balé clássico ou da dança moderna, mas antes um modo de experimentá-los em novas articulações, destilando-os e recontextualizando-os de forma crítica. De acordo com Kátia Canton (1994), a danse nouvelle francesa, exemplificada pelo estilo da coreógrafa Maguy Marin, revela a atração dos novos coreógrafos pela convenção e pela narratividade:

[...] Marin compartilha as preocupações estéticas da nova geração de coreógrafos franceses que criou a danse nouvelle. Essas preocupações podem ser resumidas, grosso modo, como uma crença de que os indivíduos não podem ser separados de seu contexto físico, narrativo e histórico. Todo material coreográfico é uma narração e, portanto, veicula algum tipo de mensagem. ${ }^{6}$

É, portanto, a partir do comportamento assumido pela geração pós-1970 de "liberar-se da memória estética" (FEBVRE, 1995) e de, ao mesmo tempo, solidarizar diferentes filiações da dança cênica, que se impõe a hipótese de que a cena híbrida daí decorrente manifesta-se como um laboratório potencial para estudar como funcionam as estratégias de teatralidade na dança.

\section{Teatralidade como um processus}

A fim de identificar traços relevantes da ocorrência da teatralidade na dança, Febvre (1995), apoiando-se nos estudos de Michel Bernard sobre o assunto, recoloca a problemática especulando em que medida a noção de teatralidade não se encontra ainda demasiadamente ligada a referências histórico-estéticas do teatro dramático e às bases mais evidentes daquilo que se designa(va) como teatral, isto é, como lugar da mimese e da representação. Isso equivale a reduzir os efeitos do teatral na dança apenas aos ditames do conteúdo semântico, utilizando tanto os meios cênicos, quanto a interpretação dos bailarinos-atores a serviço da produção de um significado indiscutível ou, falando de forma mais direta, com a finalidade de contar histórias.

6 CANTON, Kátia. E o príncipe dançou... O conto de fadas, da tradição oral à dança contemporânea. Tradução de Cláudia Sant'Ana Martins. São Paulo: Ática, 1994, p.119. 
Irena Filiberti ([1994?]) reforça a colocação de Febvre ao afirmar que o conceito de teatralidade na dança é raramente questionado em sua polivalência, restringindo-se em geral ao campo da representação: "É confundido frequentemente com 'ladainhas' narrativas ou decorativas capazes de ocultar uma ausência de pensamento e informação coreográficos"7 (FILIBERTI, [1994?], p.122). De acordo com ela, a má interpretação por parte dos coreógrafos resulta na aplicação de artifícios mirabolantes à linguagem coreográfica para a confecção de obras mais teatrais, esquecendo-se que muitas vezes a circulação do significado se encontra no próprio corpo e em seu movimento.

Uma das possibilidades de inserir a dança na corrente de discussão, liberando-a das amarras do teatro, é remontar às origens da teatralidade para compreendê-la como fenômeno extra-teatral, isto é, como matriz geradora ou estrutura que torna possível a emergência do acontecimento teatral (FEBVRE, 1995). Isso equivale, em outras palavras, a pensar a teatralidade como processo de produção da cena.

Quando se investiga a origem da palavra teatro (do grego Theatron, lugar onde se assiste a um espetáculo) recorda-se que sua existência como espaço de representação surge a partir da relação consciente entre aquele que olha e aquele que é olhado. Sua propriedade mais fundamental é a de ser "o local de onde o público olha uma ação que lhe é apresentada num outro lugar. $O$ teatro é mesmo, na verdade, um ponto de vista sobre um acontecimento [...]" (PAVIS, 1999, p. 372). É, portanto, nesse entreolhar, no intervalo que se cria entre o olho do observador e aquilo que é observado, intervalo dentro do qual o sentido pode deslizar, que a teatralidade se manifesta.

Josette Féral (2004) define teatralidade como sendo, a priori, o resultado de uma dinâmica perceptiva que une observado (sujeito ou objeto) e observador: "Mais que uma propriedade, a teatralidade aparece [...] como um 'processus' que assinala os sujeitos em processo: observado-observador" (FÉRAL, 2004, p.92). Por meio de seu olhar, o espectador cria um espaço outro diferente do cotidiano (espaço virtual ou de alteridade) que permite a emergência da ficção. A teatralidade é, assim, aquilo que força o espectador a perceber o espetacular ou o ato de representação ${ }^{8}$.

\footnotetext{
7 Traduzido do original. Cf. FILIBERTI, Irena. O visível e o invisível. In: TAMBUTI, Suzana; MOYANO, Marcelo Isse. Cuaderno de Danza 2: Aproximación a un Estudio Histórico de la Danza en el Siglo XX. Buenos Aires: Instituto de Artes del Espectáculo, [1994?], Tema 7, p.121-122.

8 A representação é aqui entendida simplesmente no sentido de algo que se diferencia da existência comum e do real.
} 
A interação entre emissores e receptores é, assim, o elemento que torna possível a produção de uma mensagem e o processo de descoberta de significados - espécie de decifração a que o espectador deve ser conduzido via materialidade do espetáculo (BARTHES, 2009a). Nesse processo de decifração estão implicados, grosso modo, os materiais cênicos empregados (gesto, movimento, palavra, sonoridade, objeto, imagem, texto), a densidade das informações (economia ou dispêndio dos elementos cênicos), as estruturas de composição (entrelaçamento das textualidades), os canais de recepção (relação palco-plateia).

Assim, o elemento inicial para se compreender a teatralidade é o olhar de um terceiro: a teatralidade "não existe como uma realidade fora do momento em que alguém está olhando; quando deixar de olhar, deixará de haver teatralidade" (CORNAGO, 2009). Trata-se, portanto, de uma operação processual, de produto inacabado, que só tem existência no momento em que o olhar do espectador o põe em funcionamento.

O teatro como lugar de onde se olha pode também ser considerado no sentido de espaço potencializador daquilo que no teatral é prioritariamente visual, isto é, na força que o teatral tem de impor-se como imagem de forma autônoma, seja a um texto, a uma narrativa racional ou a códigos e convenções culturais pré-estabelecidos, configurando possibilidades renovadas de escrituração cênica. Estas novas formas poéticas - dentre as quais a dança contemporânea se inclui - se afirmam, acima de tudo, pela presença física e simbólica e pela priorização de uma lógica sensorial mais que cognitiva, em que o corpo tem papel preponderante.

\section{O corpo como fonte privilegiada de produção da teatralidade na dança}

Ao tratar da teatralidade coreográfica, Febvre (1995, p.40) emprega uma definição extremamente propícia para a compreensão de sua especificidade na dança, deslocando o teatral do "lugar da mimese e da representação" para a "condição que possibilita a materialização 'das coisas mais instintivas'”. O instintivo deve aqui ser entendido não como impulso de libertação do inconsciente, mas como falta de vontade por parte dos criadores de teatralizarem suas danças, conforme esclarece a autora. $O$ teatral surgirá frequentemente "à força das coisas", como resultado de processos aleatórios, pela ação da intuição, pela manipulação dos diversos materiais empregados na criação que irão, aos poucos, impondo seus sentidos. O desejo preponderante não é o de fazer teatro senão o de traduzir ideias, estados, sensações. 
Ainda a esse respeito, a autora diz que a tendência do bailarino e do coreógrafo contemporâneo é trabalhar mais no trajeto ação-emoção que em direção inversa, buscando no próprio comportamento motor o acionamento dos domínios afetivo e simbólico. A dimensão somática do indivíduo já é, em si, um lugar de inscrição tanto de uma história individual, quanto de uma mitologia do corpo inserida num determinado ambiente cultural (GODARD, 2001); é, por assim dizer, um discurso sobre si mesmo e sobre o mundo circundante.

Seguindo a mesma linha de raciocínio, Michel Bernard (1976) sublinha o corpo como fonte privilegiada de produção da teatralidade, o elemento que permite tanto o exercício quanto a institucionalização da prática teatral. Quanto a esse aspecto, toda a cena contemporânea se inclinou aos problemas da corporeidade e suas manifestações. A experiência corporal se tornou o ponto de ancoragem das investigações criativas e cênicas. Decorrente disso, assistimos a um deslocamento fundamental do papel concedido ao corpo na cena, excedendo seu fim puramente (re)produtor de significado - corpo como mediador de um texto ${ }^{9}$ - para o alcance de uma forma multiexpressiva que relaciona discurso e ação, pensamento e movimento. Neste tipo de experiências cênicas, o corpo expressa predominantemente estados, intensidades, fluxos energéticos, pulsões, presenças, sensações, afastando-se da mera representação mimética da realidade.

Bernard (1976) destaca que teatralidades singulares podem ser criadas da tensão entre corpo e linguagem, variando o resultado de acordo com a dinâmica de conjunção/disjunção entre ambos. Aplicado à dança, Febvre (1995) comenta que as características do produto são fruto das possíveis ênfases dadas à corporeidade dançante, podendo configurar-se dentro de um extenso arco que vai da autorreflexividade extrema à atribuição de sentido:

A proposição particularmente árida de Michel Bernard sobre a teatralidade faz entrever como as manifestações intensivas do corpo se convertem, se

9 De acordo com Mateo Bonfitto (2006), o conceito de texto, originário da Semiótica, amplia possibilidades de interpretação e descrição dos fenômenos cênicos na medida em que concebe o espetáculo (ou texto espetacular) como rede semântica composta pelo conjunto de unidades textuais (materiais cênicos): corpo, luz, objetos, som, texto, figurinos etc. Citando M. de Marinis, ele esclarece: 'Em seu uso semiótico o termo 'texto' não designa somente as sucessões coerentes e completas dos enunciados, escritos ou orais, da língua, mas também, igualmente, toda unidade de discurso - seja essa do tipo verbal, não verbal ou misto - que resulte da coexistência de mais códigos e que possua requisitos constitutivos de completude e coerência. A partir de tal concepção, uma imagem, um conjunto de imagens, uma escultura, um filme, um trecho musical, uma sequência de sons podem ser 'textos' [...]". Cf. BONFITTO, Matteo. O ator-compositor: as ações físicas como eixo: de Stanislávski a Barba. 2.ed. São Paulo: Perspectiva, 2006a, p. 83-84 
metaforizam ou se metamorfoseiam em expressão, com efeito de sentido ou de teatro, mesmo quando se encontram totalmente à parte de uma intenção mimética ou expressiva. ${ }^{10}$

Assim, a produção de situações de linguagem ou a simples presença do intérprete em cena - ainda que ambos desprovidos de qualquer intenção de simbolizar não são mais do que formas peculiares de teatralidade na dança.

Elegendo a corporeidade do bailarino como elemento central de suas investigações, Febvre (1995) destaca alguns parâmetros a partir dos quais discute o funcionamento de certos mecanismos de teatralidade na dança contemporânea, dentre os quais estão a morfologia corporal do bailarino, sua interação com o espaço e com outros intérpretes, e a exploração de uma gestualidade cotidiana.

A autora ressalta que não é possível determinar uma teatralidade coreográfica sem deixar de fazer referência à utilização de uma gestualidade habitual, rotineira, como objeto de exploração sistemática por parte de certos criadores contemporâneos - gestualidade essa que retorna ao cotidiano e que pode conduzir a uma perda da qualidade da dança. Como perda de qualidade da dança, a estudiosa se refere à quebra total, parcial ou moderada da mobilidade dançante ${ }^{11} \mathrm{e}$ à inscrição de uma nova potencialidade no campo da representação mimética pelo emprego esporádico ou contínuo do registro da gestualidade social ou individual. Nesse caso, o empréstimo de uma gestualidade cotidiana pode tanto resultar num recurso para colocar em relevo uma intimidade ou memória própria do intérprete (dado que o gesto é em si portador de uma história e de uma carga simbólica que lhe são inerentes), quanto numa possibilidade de quebrar com o virtuosismo da dança.

A estratégia de jogar com a simplicidade dos comportamentos casuais, mais autênticos, sem cerimônias, frente a um preparo técnico-corporal preciso, será tendência significativa dos movimentos de vanguarda da dança pós- anos 1970. O trabalho com intérpretes de características morfológicas diversificadas, subvertendo o arquétipo idealizado da bailarina clássica, e com experiências físicas variadas (incluindo o emprego de não dançarinos e de outros artistas da cena) serão aspectos que terão plena participação na configuração de novas teatralidades em dança. Febvre (1995) comenta que o recurso a morfologias singulares é uma forma de aproveitar-se

\footnotetext{
${ }^{10}$ Traduzido do original. Cf. FEBVRE, Michèle. Danse contemporaine et théâtralité. Paris: Editions Chiron, 1995, $1^{\text {a }}$ Parte, Cap.3, p.47

${ }^{11}$ Quanto ao termo "mobilidade dançante", a autora refere-se às condutas espaço-temporais que se baseiam em parâmetros técnicos da dança cênica, diferenciando-as das condutas cotidianas.
} 
da infrateatralidade inscrita na corporeidade de cada bailarino, moldada não unicamente pela dança, mas pela história pessoal de cada um, com o intuito de ressaltar - e não de apagar, como no caso do balé tradicional - as diferenças individuais:

É evidente que os coreógrafos utilizam também a disparidade de corpos, sua desproporção (o pequeno, o grande, o magro ou o redondo) para contrariar as harmonias esperadas e mil vezes vistas, para opor tonicidades contrárias, para provocar tensões dramáticas entre a vulnerabilidade de um e a potência do outro, ou efeitos cômicos entre o grande e o pequeno; resumidamente, para alargar a paleta de representações do ser humano. ${ }^{12}$

A escolha por empregar, nas criações em dança, tipos físicos ecléticos e de formação artística heterogênea tem sido uma inclinação frequente por parte de inúmeros coreógrafos contemporâneos, fazendo-os integrar em cena bailarinos, atores, mímicos, músicos e, inclusive, crianças. O realce de uma presença peculiar do intérprete, de aspectos marcantes de personalidade ou de idiossincrasias cinéticas converte-se em estratégia de teatralização inerente ao corpo que dança.

Além deste, outro aspecto comum aos criadores tem sido o emprego de artifícios de prolongamento e diversificação do campo de visibilidade corporal, como o mascaramento ou a deformação por meio de objetos, figurinos, recursos de luz e projeção, num jogo de mostrar/esconder o corpo altamente significativo. A produção desses outros corpos pode vir a assumir diferentes graus de abstração, indo da mais pura materialidade (investigação dos aspectos formais) aos seus poderes espirituais (exploração de diferentes camadas de significação). Nesse caso, mesmo quando houver desejo de manifestar tensões interiores, o discurso se produzirá prioritariamente no corpo, por meio da modulação de tonicidades, das qualidades cinéticas e intensidades gestuais, escapando às dramatizações evidentes.

Para Febvre (1995), a teatralidade inerente ao corpo que dança reforça-se ainda mais pelas formas de aproximação e de contato entre os intérpretes e de sua relação com o espaço (posicionamento e orientação corporais, jogo espaço-temporal). Ela acrescenta ainda que, muito embora essas sejam formas codificadas culturalmente e valoradas socialmente, no discurso coreográfico podem não confessar seus conteúdos de forma direta, assumindo níveis simbólicos, mas também sentidos obtusos, um "terceiro sentido" conforme designação de Barthes (2009b):

Leio, recebo (provavelmente, em primeiro lugar), evidente, errático e teimoso, um terceiro sentido. Eu não sei qual o seu significado, pelo menos não consigo nomeá-lo, mas vejo bem os traços, os acidentes significantes

${ }^{12}$ Traduzido do original. Cf. FEBVRE, Michèle. Danse contemporaine et théâtralité. Paris: Editions Chiron, 1995, $2^{\mathrm{a}}$ Parte, Cap.2, p.70. 
de que este signo, desde então incompleto, é composto [...] aquele que vem 'a mais', como um suplemento que a minha intelecção não consegue absorver bem, ao mesmo tempo teimoso e fugidio, liso e esquivo, proponho chamar-Ihe o sentido obtuso. ${ }^{13}$

O sentido obtuso nos recoloca aqui na lógica do figural, cuja intenção extrapola o ficcional e representativo do movimento para expressar-se em termos de flutuações de intensidade ou circulações energéticas. A ação energética baseia-se no modelo energético de Jean François Lyotard, o qual distingue claramente o discursivo, que comunica por meio do signo e do linguístico (por exemplo, o ator que representa mimeticamente situações reais), do figural que é um acontecimento irredutível à linguagem (por exemplo, um espetáculo de dança no qual o gesto não acompanha um texto ou narrativa) e do qual só podemos suspeitar o sentido e função pelo emprego de uma lógica sensorial e cinestésica e não uma lógica do significado (PAVIS, 2005).

Ao analisar a transformação da corporeidade dançante, Michel Bernard (1990) afirma que a dança contemporânea tende a privilegiar o figural sobre o figurativo. Elucida a diferença entre as duas noções, alertando que o figurativo sempre implica na relação ilustrativa entre uma imagem e um objeto ou ainda na relação de uma imagem com outras, dentro de um conjunto composto que a liga precisamente ao objeto em foco; já o figural isola a imagem como evento único, quebrando a narração e impedindo a ilustração.

A corporeidade do bailarino resulta, assim, em elemento indispensável para se refletir sobre a produção coreográfica do ponto de vista das estratégias de teatralidade. É no corpo do bailarino que a teatralidade se codifica e se inscreve na cena, semiotizando tudo aquilo que o rodeia: espaço cênico, texto, música, cenografia, figurinos, iluminação (FÉRAL, 2004). Isso faz supor que os modos como a materialidade corporal do bailarino se elabora e se mostra tem estreito vínculo com a percepção de uma teatralidade que lhe é peculiar.

Se o corpo é fonte privilegiada de investigação de novas teatralidades, deve-se considerar que as bases técnicas e criativas sobre as quais esse corpo se constrói têm forte implicação sobre o projeto estético ao qual está vinculado. O criador/coreógrafo, ao optar por determinadas ferramentas de treinamento e criação em meio a uma variedade de outras possibilidades, está inevitavelmente realizando uma escolha quanto ao processo de significação da obra ${ }^{14}$. A teatralidade traduz-se, pois, num modo autoral

\footnotetext{
${ }^{13}$ BARTHES, Roland. O óbvio e o obtuso. Tradução de Isabel Pascoal. Lisboa, Portugal: Edições 70, 2009b, p.48-50.

${ }^{14}$ De acordo com Barthes (2009a), significação é "o processo que produz o sentido, e não o próprio sentido".
} 
que cada criador tem de manipular os elementos da linguagem cênica, sem a intenção de "transmitir uma mensagem positiva (não é um teatro de significados), mas fazer compreender que o mundo é um objeto que deve ser decifrado (é um teatro de significantes)" (BARTHES, 2009a, p.300).

Por sua mobilidade e abertura conceitual, a dança contemporânea invoca constante atualização de modelos de análise crítica e a expansão de estratégias de leitura que deem conta dos fenômenos artísticos em transformação. A noção de teatralidade apresenta-se como potente ferramenta para se refletir sobre a produção coreográfica contemporânea, pois o que indaga ante uma obra de dança já não é o que significa, senão como funciona.

\section{Referências}

ARTAUD, Antonin. O teatro e seu duplo. Tradução de Teixeira Coelho. 3.ed. São Paulo: Martins Fontes, 2006.

BARTHES, Roland. Ensaios críticos. Tradução de António Massano; Isabel Pascoal. Lisboa, Portugal: Edições 70, 2009a.

2009b. O óbvio e o obtuso. Tradução de Isabel Pascoal. Lisboa, Portugal: Edições 70,

BERNARD, Michel. L'expressivité du corps. Recherches sur lês fondements de la théâtralité. Paris: Editions Universitaires Jean-Pierre Delarge, Coll. «Corps et culture», 1976.

Les nouveaux codes corporels de la danse contemporaine. In: PIDOUX, JeanYves. La danse, art du XX siécle. Laussane: Payot Lausanne, 1990, p. 68-76.

BONFITTO, Matteo. O ator-compositor: as ações físicas como eixo: de Stanislávski a Barba. 2.ed. São Paulo: Perspectiva, 2006.

CANTON, Kátia. E o príncipe dançou... O conto de fadas, da tradição oral à dança contemporânea. Tradução de Cláudia Sant'Ana Martins. São Paulo: Ática, 1994.

CORNAGO, Óscar. ¿Qué es la teatralidad? Paradigmas estéticos de la Modernidad. Agenda Cultural Alma Máter, $n^{\circ}$ 158, 2009. Disponível em: http://201.147.150.252:8080/jspui//bitstream/123456789/1317/1/1788.pdf. Acesso em: 07 mar. 2012.

FEBVRE, Michèle. Danse contemporaine et théâtralité. Paris: Editions Chiron, 1995.

FÉRAL, Josette. Teatro, Teoria y Prática: más Allá de las Fronteras. 1.ed. Buenos Aires, Galerna, 2004.

FERNANDES, Silvia. Teatralidades contemporâneas. São Paulo: Perspectiva, 2010.

Teatralidade e Performatividade na Cena Contemporânea. Repertório, Salvador, n.16, p.11-23, 2011.

FILIBERTI, Irena. O visível e o invisível. In: TAMBUTI, Suzana; MOYANO, Marcelo Isse. Cuaderno de Danza 2: Aproximación a un Estudio Histórico de la Danza en el Siglo XX. Buenos Aires: Instituto de Artes del Espectáculo, [1994?], Tema 7, p.121-122.

GERALDI, Silvia Maria. Raízes da Teatralidade na Dança Cênica: recortes de uma tendência paulistana. 2009. 322p. Tese (Doutorado em Artes) - Instituto de Artes, Universidade Estadual de Campinas, Campinas, 2009. 
GODARD, Hubert. Gesto e percepção. In: PEREIRA, Roberto; SOTER, Silvia (Org.). Lições de Dança 3. Rio de Janeiro: UniverCidade Editora, 2001, p. 11-35.

PAVIS, Patrice. Dicionário de teatro. Tradução de J. Guinsburg; Maria Lúcia Pereira. São Paulo: Perspectiva, 1999.

A análise dos espetáculos: teatro, mímica, dança, dança-teatro, cinema. Tradução de Sérgio Sálvia Coelho. São Paulo: Perspectiva, 2005.

RAMOS, Luiz Fernando. A pedra de toque. Revista Humanidades, Brasília, edição especial, n. 52, p. 27-34, novembro de 2006. 